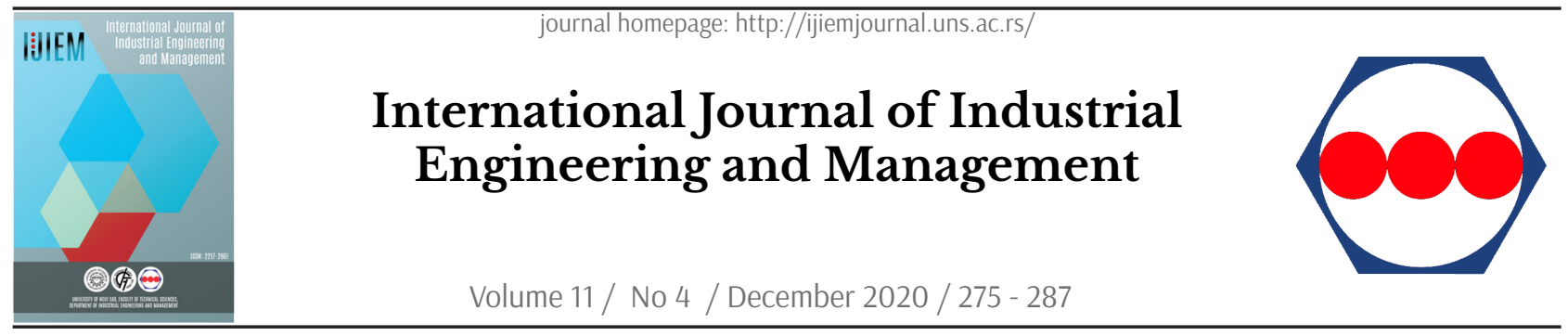

Original research article

\title{
The cumulative capability models: A contingency analysis
}

\author{
M. Vilkas *, J. Duobiene, R. Rauleckas \\ Kaunas University of Technology, Kaunas, Lithuania
}

\begin{abstract}
A B STRACT
Cumulative capability development models imply that there is a universal sequence in the development of performance capabilities. Despite the critique that such an approach does not align with contingency theory, efforts to identify which internal organizational characteristics affect the sequence of capabilities development have been limited. The study employs PLSSEM multigroup analysis and a sample of 500 production firms to reveal whether internal organizational factors result in contrasting capability development sequences. The findings reveal that strategic priority choices result in significantly different capability development paths. The study suggests that strategic priority is an important contingency factor for explaining whether an organization will follow the sand cone sequence of capability development.
\end{abstract}

\section{ARTICLE INFO}

Article history:

Received September 22, 2020

Revised December 21, 2020

Accepted December 22, 2020

Published online December 28, 2020

Keywords:

Cumulative capability development; Competitive priorities;

Contingency theory

*Corresponding author:

Mantas Vilkas

mantas.vilkas@ktu.lt

\section{Introduction}

The research on the sequence of development of performance capabilities is centered around cumulative capability development models. The proponents of the cumulative capabilities approach [1], [2] argue that organizations can excel at multiple dimensions of performance; however, the capabilities development sequence matters. One of the most accepted sequences of capability development - the sand cone model [2] - suggests that organizations should start improving quality performance, concentrating on delivery, flexibility, and, finally, cost-effectiveness. $\mathrm{Cu}-$ mulative capability development models belong to the core of the operation strategy field [3], [4] and are extensively tested and extended in various contexts [5], [6].

The parsimony of the cumulative capability sand cone model and its universality claims were among the most important reasons for its prevalence. Scholars suggest [7] that the model is based on three intertwined propositions related to universality. First, the model assumes that companies compete on the same sets of competitive capabilities. Second, the model implies that companies must succeed in all capabilities to achieve success. Finally, there is one best way to develop capabilities. Indeed, the proponents of the cumulative capability approach argued 
that the model is a universal way of the development of capabilities: "An obvious criticism of this model is that we seem to throw all contingencies overboard. The model seems to suggest that there is only one best way to achieve multiple sets of manufacturing capabilities; to some extent, this is indeed our belief" [2, p. 174].

The model was tested extensively [8]-[12], [1], [5]-[6], but the empirical support for the sand cone model was mixed. Empirical tests show that 53\% [1], $53 \%$, and $49 \%$ (in two samples) [13] of organizations may be classified as following a path of the sand cone model. The findings show that the cumulative capability development model is widely prevalent. These findings also challenged the claims of the universality of the cumulative capability development model. It was proposed that there are contingency factors that guide the sequence that organizations follow [11], [1], [13]. Empirical evidence was provided regarding the differences in the patterns of cumulative capabilities between countries and industries [14]-[15], and between industries [11]. While environmental factors are associated with capabilities development differences, contingency analysis of internal organizational factors on capabilities development is still missing [11]. In this article, we seek to shed light on whether the sand cone capabilities development sequence is dependent on competitive priorities and other internal organizational characteristics, such as the size of an organization, product complexity, type of design, manufacturing process, batch size, and extent of capacity utilization.

This study is based on data collected as a part of the European manufacturing survey in 2018. The data on a representative sample of manufacturing organizations in a country $(\mathrm{N}=500)$ were collected using a telephone-based survey method. Multigroup analysis of partial least squares structural equation modeling was used to identify the differences in the accumulation of capabilities based on the differences in competing priorities and other internal organizational characteristics. This research contributes to contingency research on cumulative capability models. The results reveal that competitive priorities are an important factor determining the sequence of competitive capabilities development. The study also reveals that other internal organizational characteristics do not result in statistically significant differences in the accumulation of capabilities.

The remainder of the paper is organized as follows. First, we review the literature on sand cone sequences and present a theoretical framework guiding our empirical research. Later, we describe the data collection procedures and methods of the study. Finally, we present the multigroup analysis results to reveal which internal organizational characteristics affect the capabilities development sequence. Finally, we theorize the findings and discuss the contribution of the results..

\section{Literature review and theoretical framework}

The prevailing model of deliberate strategy provides a framework for connecting strategic intentions, strategic actions, and performance (Skinner, 1969, Hayes and Wheelwright, 1988). Following the model, organizations are advised to select among competing priorities. The selected priorities then guide the pattern of structural and infrastructural decisions. As a result, organizations develop competitive capabilities. Strategic priorities represent the intentions for which the performance dimension or pattern of dimensions are essential and will be developed in the future. Structural and infrastructural decisions are strategic choices regarding investments in assets and the selection of operating policies [3]. Competitive capabilities are the ability to compete on the dimensions of performance relative to primary competitors in the target markets [1]. The framework is used in different ways to explain how organizations gain competitive advantage. The research on strategic configurations argues that competitive priorities relative to competitors provide the foundation for competitive advantage. In contrast, the resource-based view argues that organizational assets, which are valuable, rare, nonsubstitutable, and challenging to imitate, are fundamental to competitive advantage. Such assets lead to superior quality, delivery, flexibility, and cost-competitive performance.

Two research streams concentrate on the process of developing performance capabilities: the trade-off and the cumulative capabilities approach. The advocates of the trade-off approach [16] argue that companies cannot perform well on all dimensions because the improvement in a performance dimension results in the deterioration of another performance dimension. In contrast, the proponents of the cumulative capabilities approach [2], [19] argue that organizations can excel at all dimensions of performance; however, the capabilities development sequence matters. The sand cone model [2] suggests that organizations should start improving quality performance, concentrating on delivery, flexibility, and, finally, cost-effectiveness. The model rests on the following 
assumptions. First, quality constitutes the foundation of all capabilities [2], [10] [19]. Second, improved quality and delivery capabilities can improve flexibility and cost capabilities [10]. Third, each step in the sequence requires more learning than the previous step [10], [5]. Fourth, costs are treated as the effect or outcome of quality, delivery, and flexibility capabilities [5].

The research on the sand cone model of capabilities development attracted much interest, as it promised that a universal capabilities development sequence might exist. The model was tested extensively [8]-[12], [1], [5]-[6], but the empirical support for the sand cone model was mixed. Empirical tests show that 53\% [1], 53\%, and 49\% (in two samples) [13] of organizations may be classified as following the sand cone model's path. The findings show that while the percentage of organizations following the sequence is considerable, the sand cone is not a universal sequence of performance capability development. It has been suggested that internal and external contingencies influence the pattern of competitive performance development [1], [13].

Contingency research in operations management is intended to reveal the contextual conditions under which operations practices are effective [20]-[21]. Contingency research on sand cone sequences would reveal the external conditions and internal factors under which the sand cone sequence is supported. Empirical evidence was provided for the differences in the patterns of cumulative capabilities between countries [15], [11], [14], and industries [11]. For example, it was revealed that the sequence Q->D->C$>\mathrm{F}$, titled "the most comfortable sequence," is more prevalent in developing countries than the sand cone sequence Q->D->F->C. It was argued that emerging countries have more leverage to develop cost-competitive performance instead of flexibility competitive performance in their earlier organizational maturity stages. While the external contextual factors were associated with differences in the capabilities development sequence, the research on internal factors under which the sand cone sequence is supported is still limited. In this article, we ask whether the sand cone capabilities development sequence is dependent on competitive priorities and other internal organizational characteristics, such as the size of an organization, product complexity, type of design, manufacturing process, batch size, and extent of capacity utilization (Figure 1).

The theoretical framework guides the empirical research by identifying the internal organizational characteristics that result in differences in the accumulation of capabilities. The framework allows to test seven hypotheses:

There are statistically significant differences in accumulation quality, delivery, flexibility, and cost-competitive performance among organizations:

H1. competing on different strategic priorities;

H2. characterized by different size;

H3. producing products characterized by

different degrees of product complexity;

H4. using different types of the design process;

H5. using different types of the manufacturing process;

H6. using different batch sizes;

H7. characterized by different levels of capacity utilization.

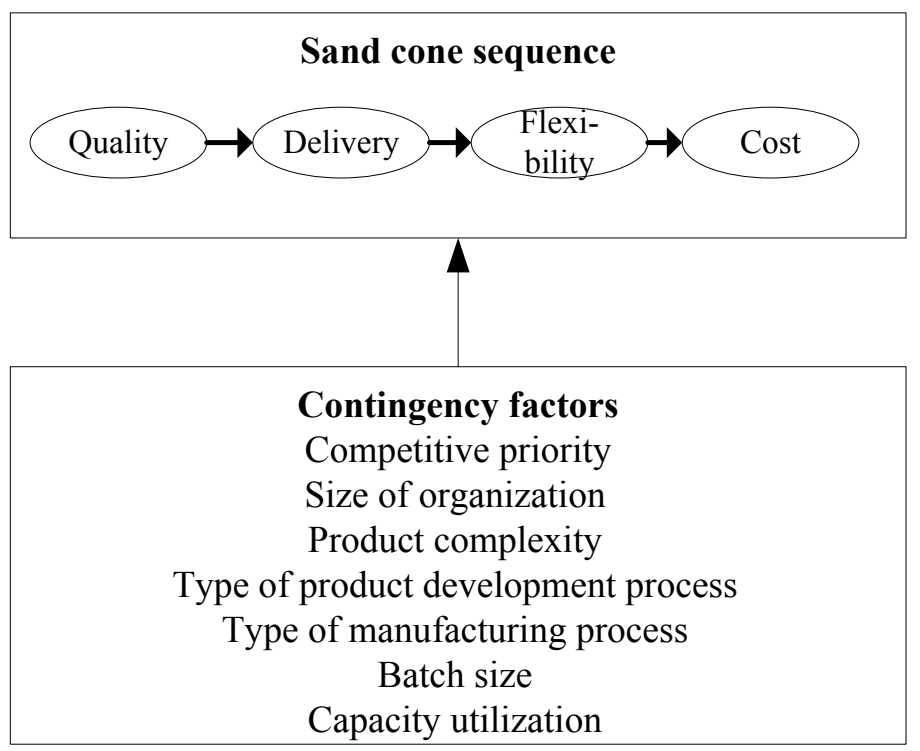

Figure 1. Internal factors affecting the sand cone sequenc 
In the next section, we describe the research design, which allows testing whether competitive priorities and other internal characteristics of an organization affect the sequence of capability development.

\section{Research method}

\subsection{Research design}

We used partial least squares structural equation modeling (PLS-SEM) to test a cumulative capability development model. Furthermore, we employed a multigroup analysis to determine if the cumulative capability development model is contingent on strategic priorities and other internal organizational characteristics. Multigroup analysis enables us to test for differences between identical models estimated for different groups of organizations [22]. The analysis reveals whether there are statistically significant differences between individual group models [22]. For example, we used multigroup analysis to compare whether the sand cone sequence of the development of performance capabilities is different among organizations, choosing quality, delivery, flexibility, and cost as their primary competitive priorities. The sample is split into four subsamples or groups based on dominating competitive priority. The path coefficients among the capabilities prescribed by the sand cone model are estimated in each group. Finally, after bootstrapping 5000 samples (Hair et al., 2016), statistically significant differences between sand cone sequences in each group were revealed. SmartPLS 3 software [23] was used for path analysis and multigroup analysis.

\subsection{Data collection and description of a sample}

Data were collected as part of the European manufacturing survey (EMS) in 2018. EMS is an international network of research institutions collecting data in their respective countries. The standardized questionnaire was used for data collection. The data were collected on individual manufacturing sites because each manufacturing site in a business unit may exhibit different performance capabilities [1]. A telephone survey was used to collect data. The data from one country were used for this research to minimize the country difference effects. The sampling frame consists of 6122 manufacturing sites covering all subsectors of manufacturing and covers the country's population of manufacturing sites. The respondents were technical managers or production managers at manufacturing sites with more than 200 employees, and general managers, technical managers, and production managers at manufacturing sites with fewer than 200 employees. A stratified random sampling procedure was used. Strata were defined in terms of four regions of the country and four size classes of organizations (2-19, 20-49, 50-99, 100-249 employees). Then 2330 manufacturing sites were contacted. The effective sample is 500 manufacturing sites, which constitutes a $215 \%$ response rate. The sample characteristics are presented in Table 1.

The effective sample has adequate representation for all firm sizes, regions of the country, and all manufacturing subsectors.

\subsection{Measures}

The selection of measures of competitive performance was based on an extensive review of the literature. Several approaches to the operationalization of performance dimensions are available [1], [12]-]13] [25]-[24]. We used the operationalization proposed by Schroeder and his coauthors [1] for the measurement of quality, delivery, flexibility, and cost performance (Table 2). The respondents were asked to indicate how well their factory performed compared to its competitors within their industry along the different performance dimensions. Competitive priorities were measured by asking respondents to rank six competitive priorities (product price, product quality, customization to customers' demands, delivering on schedule/ short delivery times, innovative products and services) in order of importance, anchored with 1 as "most important" and 6 as "least important." The assignment of equal importance was not allowed. The organizations that use strategic priorities of services [17] and innovative products [18] were not included in the analysis due to low frequencies. The scales of performance capabilities and internal organizational factors are provided in Annex 1.

\subsection{Measurement model}

Partial squares structural equation modeling was employed for the confirmatory factor analysis (CFA) of the measurement model. The characteristics of the measurement model are presented in Table 2 .

The reliability of the employed scales was measured by Cronbach's alpha and the composite reliability score. Although reliability estimates are above 0,95 thresholds, the content validity of the original scales is maintained. EFA suggested four factors, as 
Table 1. Sample characteristics

\begin{tabular}{|c|c|c|}
\hline \multirow{2}{*}{$\begin{array}{l}\text { Demographic characteristics } \\
\text { Industry }\end{array}$} & \multicolumn{2}{|c|}{$N=500$} \\
\hline & Number & $\%$ \\
\hline Engineering & 125 & 25.0 \\
\hline Food & 64 & 12.8 \\
\hline Textiles & 70 & 14.0 \\
\hline Wood and paper & 156 & 31.2 \\
\hline Chemicals and chemistry & 11 & 2.2 \\
\hline Other & 74 & 14.8 \\
\hline Number of employees & Number & $\%$ \\
\hline$<20$ & 300 & 60.0 \\
\hline $20-49$ & 108 & 21.6 \\
\hline $50-99$ & 44 & 8.8 \\
\hline $100-249$ & 34 & 6.8 \\
\hline$>250$ & 14 & 2.8 \\
\hline Competitive priority & Number & $\%$ \\
\hline Product quality & 248 & 49.6 \\
\hline Customization for customer & 104 & 20.8 \\
\hline Fast/on-time delivery & 60 & 12 \\
\hline Product price & 48 & 9.6 \\
\hline Innovative products & 28 & 5.6 \\
\hline Services & 12 & 2,4 \\
\hline Respondent position & Number & $\%$ \\
\hline Head/director & 334 & 66.8 \\
\hline Technical manager, director, head of production & 162 & 32.4 \\
\hline Branch head & 4 & 0.8 \\
\hline
\end{tabular}

Table 2. The characteristics of the measurement model

\begin{tabular}{|c|c|c|c|c|c|c|c|}
\hline Construct & Item & Code & $\begin{array}{l}\text { Factor } \\
\text { loadings }\end{array}$ & p-values & $\begin{array}{l}\text { Cronbach } \\
\text { alpha }\end{array}$ & CR & AVE \\
\hline \multirow{2}{*}{ Quality } & $\begin{array}{l}\text { Product overall quality } \\
\text { performance }\end{array}$ & Q1 & 0,962 & 0,000 & 0,914 & 0,959 & 0,921 \\
\hline & $\begin{array}{l}\text { Conformance to } \\
\text { specification }\end{array}$ & Q2 & 0,958 & 0,000 & & & \\
\hline \multirow[b]{2}{*}{ Delivery } & On-time delivery performance & D1 & 0,955 & 0,000 & 0,911 & 0,957 & 0,918 \\
\hline & $\begin{array}{l}\text { Delivery speed } \\
\text { (from order until delivery) }\end{array}$ & D2 & 0,961 & 0,000 & & & \\
\hline \multirow{3}{*}{ Flexibility } & $\begin{array}{l}\text { Ability to adjust production } \\
\text { volumes }\end{array}$ & $\mathrm{F} 1$ & 0,925 & 0,000 & 0,92 & 0,949 & 0,861 \\
\hline & $\begin{array}{l}\text { Ability to produce a range of } \\
\text { products }\end{array}$ & $\mathrm{F} 2$ & 0,925 & 0,000 & & & \\
\hline & $\begin{array}{l}\text { Speed on new product } \\
\text { introduction into the plant }\end{array}$ & F3 & 0,934 & 0,000 & & & \\
\hline \multirow{3}{*}{ Cost } & Unit cost & $\mathrm{C} 1$ & 0,952 & 0,000 & 0,938 & 0,96 & 0,89 \\
\hline & Manufacturing overhead cost & $\mathrm{C} 2$ & 0,965 & 0,000 & & & \\
\hline & Inventory turnover & $\mathrm{C} 3$ & 0,913 & 0,000 & & & \\
\hline
\end{tabular}


expected, with high loadings and low cross-loadings. Loadings obtained by CFA are in Table 2. Convergent validity is demonstrated on the item level through statistically significant loadings exceeding the threshold of 0,708 and on the construct level through the average variance extracted (AVE) being not less than 0,5 for every construct (Hair et al., 2016). Discriminant validity was established by the absence of high cross-loadings, matching the Fornell-Larcker criterion, and passing the heterotrait-monotrait ratio (HTMT) test (Annex 2).

\section{Results}

\subsection{The manifestation of the sand cone sequence in the sample}

The analysis of the results is presented in the following way. First, we verify the sand cone model using the sample data. The accumulation of quality, delivery, flexibility, and cost capabilities is confirmed if the path coefficients are positive and statistically significant. Then, we apply multigroup analysis to test for significant differences among path coefficients between two groups based on the contingency variables identified in the literature review.

The path model was developed according to the classic cumulative capability model proposed by Ferdows and de Meyer [2]. In the model, quality competitive performance is the antecedent of delivery performance, competitive delivery performance is the antecedent of flexibility performance, and competitive flexibility performance is the antecedent of cost performance.

The path analysis revealed the relationships among the latent variables of the sand cone model (Figure 2). The latent variables are bounded by the medium relations in the model. Schroeder et al. (2011) found a stronger association between performance capabilities (Q->D, 0,61**; D->F, $0,7^{* *}$, and $\left.\mathrm{F}->\mathrm{C}, 0,64^{* *}\right)$. However, country differences may exist, where the accumulation of capabilities may be higher in economies that differ in their development stage [14]. On the other hand, other authors [7], [5] have found very similar relationships among the constructs of the model $\left(\mathrm{Q}->\mathrm{D}, 0,42^{*} ; \mathrm{D}->\mathrm{F}, 0,4^{*}\right.$, and $\left.\mathrm{F}->\mathrm{C}, 0,26^{*}\right)$. In general, the cumulative capability model's testing provided results consistent with the results of other studies. In the next section, we proceed with the contingency analysis of the model.

\subsection{The contingency analysis of the sand cone sequence}

Multigroup analysis [26] was performed to test whether the sand cone model is contingent on internal organizational characteristics such as competitive priorities, the size of an organization, product complexity, the type of product development process, the type of manufacturing process, the size of the batch, and the extent of capacity utilization. The analysis reveals that the sand cone capabilities development sequence is dependent on competitive priorities. There are no statistically significant differences in the accumulation of capabilities in groups based on other internal characteristics. The sand cone models' characteristics that are based on contingency variables and the extent and statistical significance of differences among models are provided in Annex 3.

The analysis of the sand cone capability development sequence of organizations that prioritize contrasting competitive priorities reveals statistically significant differences among the accumulation of capabilities. The sand cone model is observed; the path coefficients between pairs of capabilities are substantial and statistically significant only among the organizations that prioritize quality as a strategic priority (Figure 3 ). Within organizations that compete for delivery, the accumulation of quality and delivery, delivery, and flexibility is observed. If an organization chooses competitive priorities of flexibility or cost, then only quality and delivery capabilities are posi-

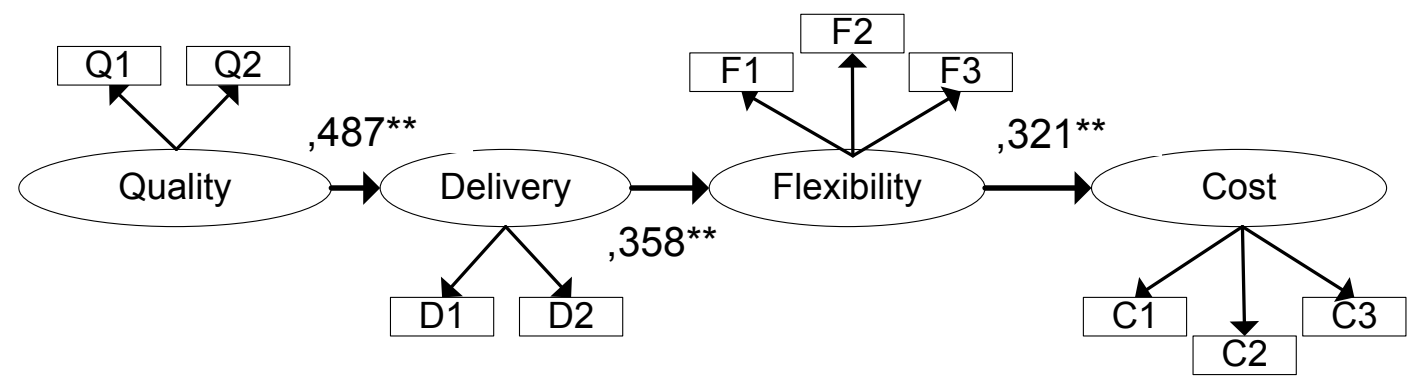

Figure 2. The cumulative capability development model $(\mathrm{N}=397)$ 
tively related at a statistically significant level.

The Q->D relationship is statistically and significantly different at $0,15^{*}(\mathrm{p}=0,028)$ among groups of organizations that emphasize quality to cost, indicated as difference D1 in Figure 2. The D->F relationship is statistically and significantly different at $0,313^{*}$ $(\mathrm{p}=0,021)$ among groups of organizations that prioritize quality to flexibility (D2). Estimates of the F->C relationship are statistically and significantly different at $0.400^{*}(\mathrm{p}=0,03)$ among organizations that compete on quality versus delivery (D3). Finally, the D->F relationship is statistically and significantly different at $0,559^{*}(\mathrm{p}=0,034)$ among groups of organizations that prioritize delivery to cost (D4). In summary, the findings reveal that the sand cone capabilities development sequence tends to manifest if organizations choose to compete on quality. Organizations that choose to compete on other strategic priorities tend to follow different paths of capabilities development. The Q->D relationship is universal, despite strategic priority choices regarding quality, delivery, flexibility, or cost.

The results show no statistically significant differences in the accumulation of capabilities in groups based on other internal characteristics, such as the size of an organization, product complexity, type of product development process, type of manufacturing process, batch size, or extent of capacity utilization. However, the sand cone accumulation of capabilities is not manifested in all groups of organizations. The sand cone sequence is observed in groups of organizations with the following characteristics: fewer than 20 and more than 20 employees; produce in a single unit; small or large batches; and operate over $90 \%$ of capacity and less than $90 \%$ capacity. However, the sand cone sequence does not hold consistently when other organizational characteristics are considered. For example, the sand cone pattern is observed in organizations whose products are characterized by medium complexity but not in companies producing simple $(\mathrm{Q}->\mathrm{D}$ at $0,275, \mathrm{p}=0,068)$ or complex products $(\mathrm{D}->\mathrm{F}$ at $0,252, \mathrm{p}=0,055)$. The accumulation of capabilities remains in organizations that develop products according to customer specifications and as a standard program from which the customer can choose. However, it does not hold in organizations that develop products according to a standardized basic program incorporating customer-specific options (F->C at $0,279, \mathrm{p}=0,082)$. We confirm the sand cone capabilities development sequence in organizations that manufacture upon receipt of a customer order, i.e., made-to-order products. However, we do not

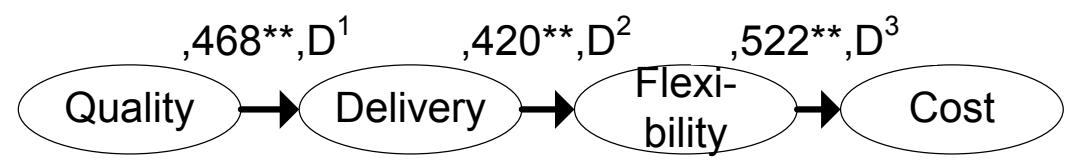

Model 1: The sand cone sequence when an organization prioritizes the strategic priority of quality

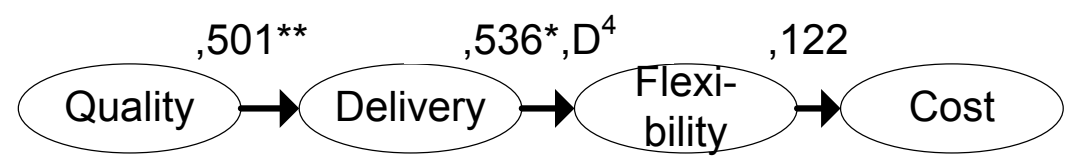

Model 2: The sand cone sequence when an organization prioritizes the strategic priority of delivery

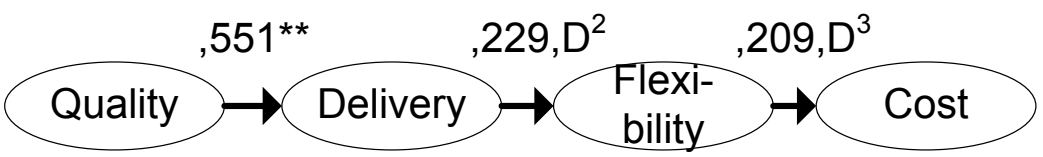

Model 3. The sand cone sequence when an organization prioritizes the strategic priority of flexibility

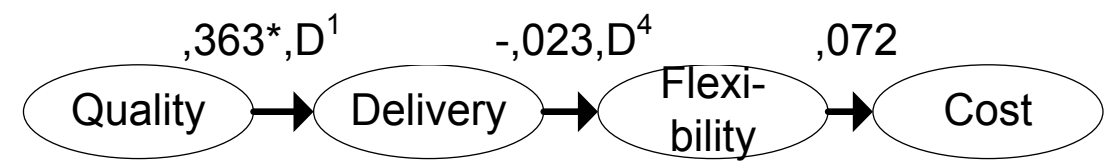

Model 4. The sand cone sequence when an organization prioritizes the strategic priority of cost

Figure 3. The sand cone model of in groups of organizations that prioritize contrasting competitive priorities 
confirm it in organizations that manufacture to stock (prior to customer orders) (Q->D at $0,289, \mathrm{p}=0,112)$. In the next section, we discuss the findings.

\section{Discussion}

In this article, we sought to reveal whether the sand cone capabilities development sequence is dependent on competitive priorities or other internal organizational characteristics, such as the size of an organization, product complexity, type of design, manufacturing process, batch size, and extent of capacity utilization. First, we confirmed that the sand cone pattern is manifested in our sample of 500 organizations. Second, we performed a multigroup analysis to reveal the sand cone model's differences in groups of organizations characterized by the selected contingency variables. Our efforts contribute to studies of cumulative capability models and the operations strategy field in several ways.

First, our empirical results confirm that the choice of strategic priority is an important contingency factor predicting whether the sand cone pattern of capability development will be followed. In addition, our findings do not show that other internal characteristics, such as the size of an organization, product complex- ity, type of design, manufacturing process, batch size, or extent of capacity utilization result in statistically significant differences in the sand cone sequence. A summary of our findings is provided in Table 3.

We confirm hypothesis H1 out of the seven hypotheses, proposing statistically significant differences in accumulation quality, delivery, flexibility, and cost-competitive performance among organizations that compete on different types of strategic priorities and differ in other internal organizational characteristics.

The findings show that the sand cone pattern is observed despite the size of the organization, size of the batch, and capacity utilization. The sand cone pattern is not observed across all types of competitive priorities, product development processes, manufacturing processes, or product complexity. For example, sand cone patterns are observed in organizations that produce medium complexity products, but they are not observed in organizations producing simple or complex products. These findings constitute an important result of the study, and possible explanations of the reasons for the sand cone pattern's instability are warranted.

Second, our findings show that the sand cone pattern of capability development is evident among organizations that choose quality as their competitive pri-

Table 3. Summary of the findings of the contingency analysis of the san cone model

\begin{tabular}{|c|c|c|c|c|}
\hline The contingency factor & $\begin{array}{l}\text { Hypotheses } \\
\text { testing }\end{array}$ & $\begin{array}{c}\text { Does the sand cone pattern hold in groups characte } \\
\text { contingency variables? }\end{array}$ & rized by & $\begin{array}{l}\text { Are diffe ences } \\
\text { statistically significant }\end{array}$ \\
\hline \multirow{4}{*}{ Competitive priority } & \multirow{4}{*}{ Confirme } & Quality & Yes & \multirow{4}{*}{ Yes } \\
\hline & & Delivery & No & \\
\hline & & Flexibility & No & \\
\hline & & Cost & No & \\
\hline \multirow{2}{*}{ Company size } & \multirow{2}{*}{ Rejected } & Less than 20 employees & Yes & \multirow{2}{*}{ No } \\
\hline & & 20 and more employees & Yes & \\
\hline \multirow{3}{*}{ Product complexity } & \multirow{3}{*}{ Rejected } & Simple products & No & \multirow{3}{*}{ No } \\
\hline & & Medium complexity products & Yes & \\
\hline & & Complex products & No & \\
\hline \multirow{3}{*}{$\begin{array}{l}\text { Type of product develop- } \\
\text { ment process }\end{array}$} & \multirow{3}{*}{ Rejected } & According to customer specificatio & Yes & \multirow{3}{*}{ No } \\
\hline & & $\begin{array}{l}\text { Standardized basic program incorporating cus- } \\
\text { tomer-specific option }\end{array}$ & No & \\
\hline & & $\begin{array}{l}\text { a standard program from which the customer can } \\
\text { choose }\end{array}$ & Yes & \\
\hline \multirow{2}{*}{$\begin{array}{l}\text { Type of manufacturing } \\
\text { process }\end{array}$} & \multirow{2}{*}{ Rejected } & Make-to-stock & No & \multirow{2}{*}{ No } \\
\hline & & Make-to-order & Yes & \\
\hline \multirow{3}{*}{ Batch size } & \multirow{3}{*}{ Rejected } & Single unit production & Yes & \multirow{3}{*}{ No } \\
\hline & & Small or medium batch & Yes & \\
\hline & & Large batch & Yes & \\
\hline \multirow{2}{*}{ Capacity utilization } & \multirow{2}{*}{ Rejected } & Operating at production frontier & Yes & \multirow{2}{*}{ No } \\
\hline & & Operating below production frontier & Yes & \\
\hline
\end{tabular}


ority. The companies that choose other competitive priorities, such as delivery, flexibility, or cost, follow other capability development sequences. The sand cone pattern in the complete sample is manifested with decreasing direct effects $\left(\mathrm{Q}->\mathrm{D}, 0,487^{*}\right.$ * ; $->\mathrm{F}$, $0,358^{* *}$, and $\left.\mathrm{F}->\mathrm{C}, 0,321^{* *}\right)$. The direct effects of a pattern among organizations that compete on quality become more uniform and tend to increase instead of decrease (Q->D, $0,468^{* *} ; \mathrm{D}->\mathrm{F}, 0,42^{* *}$, and F->C, $\left.0,522^{* *}\right)$. The extent of accumulation considering direct and indirect effects is substantial (Table 4).

The extent of the indirect effects of quality on flexibility and cost, and the indirect effects of delivery on cost is especially intriguing. The results reveal that an increase in quality results in a direct increase in delivery competitive performance $\left(0,468^{* *}\right)$. It also increases competitive performance in terms of flexibility $\left(0,197^{* *}\right)$ and cost $\left(0,103^{* *}\right)$. Such indirect effects reveal the importance of quality competitive performance on other sand cone competitive performance capabilities. The accumulation of competitive performance through direct and indirect effects predicted by the sand cone model [2], [10] is manifested among the organizations that compete on quality. The sand cone sequence proposes that cost performance results from perfected quality, delivery, and flexibility capabilities [10], [5]. Our results show that cost performance benefits from increased quality $\left(0,103^{* *}\right)$, delivery $\left(0,219^{* *}\right)$, and flexibility $\left(0,522^{* *}\right)$ performances. This finding allows quantification of the extent of the accumulation of sand cone performance capabilities among organizations characterized by quality and competitive performance.

Finally, previous research showed that 53\% [1], $53 \%$ and $49 \%$ (in two samples) [13], and 52\% [5] of companies follow the sand cone pattern of improvement in capabilities. However, previous research has provided conflicting insights into which contingency variables may account for these organizations. Our results suggest that the choice of the competitive capability of quality may be responsible for the manifestation of the sand cone sequence. A total of 49,5\% of companies in our sample report competing on the strategic priority of quality (Table 1). Unfortunately, the other studies that observe the prevalence of the sand cone sequence do not provide the frequencies of organizations competing on different strategic priorities in their samples. In our case, the part of the sample competing on strategic priority (i.e., 49,5\%) is similar to the overall measured prevalence of the sand cone sequence in other studies (approx. 50\%) [1], [5], [13]. The numbers may coincide accidentally; however, our contingency analysis reveals that the choice of strategic priority of quality is a strong predictor of whether the sand cone sequence of capabilities development will be followed.

\section{Conclusions}

The article reports the results of contingency analysis performed to reveal whether the sand cone capabilities development sequence is dependent on competitive priorities and other internal organizational characteristics, such as the size of an organization, product complexity, type of design, manufacturing process, batch size, and extent of capacity utilization. We find that the choice of strategic priority results in statistically and significantly different development paths. The choice of strategic priority of quality results in the sand cone sequence of cumulation of capabilities. The choice of other strategic priorities, such as delivery, flexibility, and cost, results in alternate sequences of development of capabilities. The previous results show that the sand cone sequence is followed by approximately $50 \%$ of organizations. Our results suggest that this percentage may be solely explained by one contingency factor: the choice of strategic priority of quality.

Several limitations characterize the research. The reliability values of the quality, delivery, cost, and flexibility performance dimensions are over 0,9. High values of reliability measure indicate that items are measuring the same dimension of the construct instead of measuring different dimensions of the construct. The groups of companies that are characterized by low cost $(\mathrm{N}=48)$ and delivery $(\mathrm{N}=60)$ competitive priorities are smaller comparing with a group of organizations characterized by quality $(\mathrm{N}=248)$ and flexibility $(\mathrm{N}=104)$ competitive priorities. However,

Table 4. The direct and indirect effects of sand cone sequences among o ganizations that are characterized by strategic priority of quality

\begin{tabular}{lllll}
\hline & Quality & Delivery & Flexibility & Cost \\
\hline Quality & - & $0,468^{* *}$ & $0,197^{\star *}$ & $0,103^{\star *}$ \\
Delivery & - & - & $0,42^{\star *}$ & $0,219^{\star *}$ \\
Flexibility & - & - & - & $0,522^{\star *}$ \\
Cost & - & - & - & - \\
\hline
\end{tabular}


this weakness is mitigated in part by bootstrapping procedures.

Further contingency research on cumulative capability models could also consider the following things. This paper reveals that sand cone sequence of development of capabilities is characteristic to companies that compete on quality. Further research could reveal what sequences are characteristic to companies that compete on delivery, cost, or flexibility competitive priorities. Second, there is a gap of knowledge on the mechanisms of accumulation of competitive performance capabilities. Finally, other empirical methods that could support the sequentially of development of capabilities would be welcomed in the future research of cumulative capability models.

\section{Funding}

This work was supported by the Research Council of Lithuania (grant number S-MIP-17-128).

\section{References}

[1] R.G. Schroeder, R. Shah, and D. Xiaosong Peng, "The cumulative capability 'sand cone' model revisited: A new perspective for manufacturing strategy," International Journal of Production Research, vol. 49, no.16, pp. 4879-4901, 2011.

[2] K. Ferdows and A. de Meyer, "Lasting improvements in manufacturing performance: In search of a new theory," Journal of Operations Management, vol. 9, no. 2, pp. 168-184, 1990.

[3] E.D. Rosenzweig and G.S Easton, "Tradeoffs in manufacturing? A meta-analysis and critique of the literature," Production and Operations Management,' vol.19, no.2, pp. 127-141, 2010.

[4] K. K. Boyer, M., Swink, and E. D. Rosenzweig, "Operations strategy research in the POMS journal," Production and Operations Management, vol. 14, no. 4, pp. 442-449, 2005.

[5] S. Boon-Itt, and C. Y. Wong, "Empirical investigation of alternate cumulative capability models: a multi-method approach," Production Planning \& Control, vol. 27, no. 4, pp. 299-311, 2016.

[6] S. Gold, R. Schodl, and G. Reiner, "Cumulative manufacturing capabilities in Europe: Integrating sustainability into the sand cone model," Journal of Cleaner Production, vol. 166, pp. 232-241, 2017.

[7] M. Hallgren, J. Olhager and R.G. Schroeder, "A hybrid model of competitive capabilities. International Journal of Operations \& Production Management," vol. 31, no. 5, pp. 511-526, 2011.

[8] M.A. Noble, "Manufacturing strategy: testing the cumulative model in a multiple country context," Decision Sciences, vol. 26, no. 5, pp. 693-721, 1995.

[9] M.A. Noble, "Manufacturing competitive priorities and productivity: an empirical study," International Journal of Operations \& Production Management,' vol. 17, no.1/2, pp. 85-99, 1997.

[10] E.D. Rosenzweig and A.V. Roth, "Towards a theory of competitive progression: evidence from high-tech manufacturing," Production and Operations Management, vol.13, no. 4, pp. 354-368, 2004.
[11] B. B. Flynn and E. J. Flynn, "An exploratory study of the nature of cumulative capabilities," Journal of Operations Management, vol. 22, no. 5, pp. 439-457, 2004.

[12] A. Grossler and A. Grubner, "An empirical model of the relationships between manufacturing capabilities", International Journal of Operations and Production Management, vol. 26, no. 5, pp. 458-485, 2006.

[13] R. Narasimhan and T. Schoenherr, "Revisiting the progression of competitive capabilities: results from a repeated cross-sectional investigation," International Journal of Production Research, vol. 51, no. 22, pp. 6631-6650, 2013.

[14] K. Amoako-Gyampah and M. Acquaah, "Manufacturing strategy, competitive strategy and firm performance: An empirical study in a developing economy environment", International journal of production economics, vol. 111, no. 2, pp. 575-592, 2008.

[15] L. M. Corbett and G. S. Claridge, "Key manufacturing capability elements and business performance," International Journal of Production Research, vol. 40, no. 1, pp.109-131, 2002.

[16] W. Skinner, "Manufacturing strategy on the "S" curve," Production and Operations Management, vol. 5, no. 1, pp. 3-13, 1996.

[17] U. Marjanovic, B. Lalic, N. Medic, J. Prester, and I. Palcic, "Servitization in manufacturing: role of antecedents and firm characteristics," Int. J. Ind. Eng. Manag., vol. 10, no. 2, pp. 133-144, 2020.

[18] B. Lalic, N. Medic, M. Delic, N. Tasic, and U. Marjanovic, "Open innovation in developing regions: An empirical analysis across manufacturing companies,” Int. J. Ind. Eng. Manag., vol. 8, no. 3, pp. 111-120, 2017.

[19] C. Corbett, and L. Van Wassenhove, "Trade-offs? What trade-offs? Competence and competitiveness in manufacturing strategy," California management review, vol. 35, no. 4, pp. 107-122, 1993.

[20] M. Ketokivi and R. Schroeder, "Manufacturing practices, strategic fit and performance: a routine-based view," International Journal of Operations \& Production Management, vol. 24, no. 2, pp. 171-191, 2004.

[21] R., Sousa and C. A. Voss, "Contingency research in operations management practices," Journal of Operations Management, vol. 26, no. 6, pp. 697-713, 2008.

[22] J. F. Hair Jr, G. T. M. Hult, C. Ringle and M. Sarstedt, "A primer on partial least squares structural equation modeling (PLS-SEM), Sage Publications, 2016.

[23] C.M. Ringle, S. Wende, and J.-M. Becker, "SmartPLS 3," Boenningtedt: SmartPLS GmbH, http://www.smartpls.com, 2015.

[24] R. Narasimhan, M Swink, and S. W. Kim, "Disentangling leanness and agility: an empirical investigation,” Journal of operations management, vol 24, no 5, pp. 440-457, 2006.

[25] P. J. Singh, F. Wiengarten, A. A. Nand, and T. Betts, "Beyond the trade-off and cumulative capabilities models: alternative models of operations strategy," International Journal of Production Research, vol 53, no 13, pp. 4001-4020, 2015.

[26] M. Sarstedt, J. Henseler, and C. M. Ringle, "Multigroup analysis in partial least squares (PLS) path modeling: Alternative methods and empirical results. In Measurement and research methods in international marketing", Emerald Group Publishing Limited, 2011. 


\section{Annex A. Scales of measurement of performance capabilities and contingency factors}

Indicate well your factory performed compared to its competition within your industry along the different performance dimensions (anchors: poor or low end of industry; average; superior)

Product overall quality performance

Product conformance

On-time delivery performance

Delivery speed (from the order until delivery)

Ability to adjust production volumes

Ability to produce a range of products

Speed on new product introduction into the plant

Unit cost

Manufacturing overhead cost

Inventory turnover

\section{Competitive priorities}

Please rank the following competitive factors in order of significance to distinguish your factory positively from competitors. Please rank from 1 to 6,1 indicating "the most important". Please do not assign equal importance to any factors.

Product price

Product quality

Customization to customers' demands

Delivering on schedule/short delivery times

Innovative products

Services

Which of the following characteristics best describes your main product or line of products?

\section{Product complexity}

- Simple products

- Products with medium complexity

- Complex products

\section{Product development}

- According to customers' specification

- As a standardized basic program incorporating customer-specific options

- For a standard program from which the customer can choose options

- Does not exist in this factory

\section{Manufacturing}

- Upon receipt of customer's order, i.e. made-to-order

- Final assembly of the product is carried out upon receipt of customer's order, i.e. assembly-to-order

- To stock (before customer's order)

- Does not exist in this factory

\section{Batch or lot size}

- Single unit production

- Small or medium batch/lot

- Large batch/lot

\section{Capacity utilization}

Degree of manufacturing capacity utilization (average in 2017)

\section{Annex 2 The measurement model}

\section{Cross-Loadings}

\begin{tabular}{lllll}
\hline & Quality & Delivery & Cost & Flexibility \\
\hline Q068_1 & $\mathbf{0 , 9 6 2}$ & 0,479 & 0,268 & 0,373 \\
Q068_4 & $\mathbf{0 , 9 5 8}$ & 0,455 & 0,264 & 0,399 \\
Q069_2 & 0,458 & $\mathbf{0 , 9 5 5}$ & 0,337 & 0,319 \\
Q069_5 & 0,475 & $\mathbf{0 , 9 6 1}$ & 0,366 & 0,365 \\
Q070_1 & 0,237 & 0,335 & $\mathbf{0 , 9 5 2}$ & 0,317 \\
Q070_2 & 0,272 & 0,319 & $\mathbf{0 , 9 6 5}$ & 0,302 \\
Q070_3 & 0,277 & 0,388 & $\mathbf{0 , 9 1 3}$ & 0,287 \\
Q071_1 & 0,367 & 0,335 & 0,335 & $\mathbf{0 , 9 2 5}$ \\
Q071_4 & 0,385 & 0,302 & 0,262 & $\mathbf{0 , 9 2 5}$ \\
Q071_5 & 0,369 & 0,355 & 0,29 & $\mathbf{0 , 9 3 4}$ \\
\hline
\end{tabular}

Fornell-Larcker Criterion

\begin{tabular}{lllll}
\hline & Cost & Delivery & Flexibility & Quality \\
\hline Cost & 0,943 & & & \\
Delivery & 0,367 & 0,958 & & \\
Flexibility & 0,321 & 0,358 & 0,928 & \\
Quality & 0,277 & 0,487 & 0,402 & 0,96 \\
\hline
\end{tabular}

Heterotrait-Monotrait Ratio (HTMT)

\begin{tabular}{lllll}
\hline & Cost & Delivery & Flexibility & Quality \\
\hline Cost & & & & \\
Delivery & 0,397 & & & \\
Flexibility & 0,343 & 0,389 & & \\
Quality & 0,3 & 0,533 & 0,439 & \\
\hline
\end{tabular}




\section{Annex 3 The results of the multigroup analysis}

\section{Competitive priority}

\begin{tabular}{llllllll}
\hline $\begin{array}{l}\text { Competitive } \\
\text { priority }\end{array}$ & $\mathrm{N}$ & $\mathrm{Q}->\mathrm{D}$ & $\mathrm{p}$-value & $\mathrm{D}->\mathrm{F}$ & $\mathrm{p}$-value & F->C & p-value \\
\hline Quality & 248 & $0,468^{* *}$ & 0 & $0,42^{* *}$ & 0 & $0,522^{* *}$ & 0 \\
Delivery & 60 & $0,501^{* *}$ & 0,001 & $0,536^{* *}$ & 0,002 & 0,122 & 0,578 \\
Flexibility & 104 & $0,551^{* *}$ & 0 & 0,229 & 0,131 & 0,209 & 0,204 \\
Cost & 48 & $0,363^{*}$ & 0,022 & $-0,023$ & 0,9 & 0,072 & 0,722 \\
\hline
\end{tabular}

\begin{tabular}{llllllll}
\hline & $\begin{array}{l}\text { Quality -Flexi- } \\
\text { bility }\end{array}$ & p-Value & Quality -Delivery & p-Value & Quality -Cost & p-Value & $p$-value \\
\hline Q-> D & 0,192 & 0,115 & 0,033 & 0,853 & $0,105^{*}$ & 0,028 & 0 \\
D -> F & $0,313^{*}$ & 0,021 & 0,116 & 0,573 & 0,443 & 0,068 & 0,578 \\
F -> C & 0,083 & 0,766 & $0,4^{*}$ & 0,03 & 0,45 & 0,608 & 0,204 \\
& Delivery -Cost & p-Value & Flexibility-Cost & p-Value & Delivery - Flexibility & p-Value & 0,722 \\
Q-> D & 0,138 & 0,709 & 0,188 & 0,309 & 0,05 & 0,759 \\
D -> F & $0,559^{*}$ & 0,034 & 0,252 & 0,767 & 0,307 & 0,210 \\
F $>$ C & 0,05 & 0,848 & $-0,518$ & 0,352 & 0,087 & 0,759 \\
\hline
\end{tabular}

\section{Company size}

\begin{tabular}{|c|c|c|c|c|c|c|c|}
\hline Company size & $\mathrm{N}$ & Q->D & p-Value & $\mathrm{D}->\mathrm{F}$ & p-Value & $\mathrm{F}->\mathrm{C}$ & p-Value \\
\hline $\begin{array}{l}\text { Less than } 20 \\
\text { employees }\end{array}$ & 300 & $0,459 * *$ & 0 & $0,344^{* *}$ & 0 & $0,391 * *$ & 0 \\
\hline $\begin{array}{l}\text { More than } 20 \\
\text { employees }\end{array}$ & 200 & $0,532^{* *}$ & 0 & $0,377^{* *}$ & 0 & $0,23 * *$ & 0,024 \\
\hline & \multicolumn{3}{|c|}{ Less than 20- More than 20} & \multicolumn{4}{|l|}{ p-Value } \\
\hline Q-> D & \multicolumn{3}{|l|}{0,073} & \multicolumn{4}{|l|}{0,477} \\
\hline$D \rightarrow F$ & \multicolumn{3}{|l|}{0,032} & \multicolumn{4}{|l|}{0,787} \\
\hline $\mathrm{F} \rightarrow \mathrm{C}$ & \multicolumn{3}{|l|}{0,161} & \multicolumn{4}{|l|}{0,18} \\
\hline
\end{tabular}

\section{Product complexity}

\begin{tabular}{|c|c|c|c|c|c|c|c|}
\hline $\begin{array}{l}\text { Product } \\
\text { complexity }\end{array}$ & $\mathrm{N}$ & Q->D & p-Value & $D->F$ & p-Value & $\mathrm{F}->\mathrm{C}$ & $\mathrm{p}$-Value \\
\hline Simple & 83 & 0,275 & 0,068 & $0,31^{*}$ & 0,027 & 0,251 & 0,151 \\
\hline Medium & 288 & $0,479 * *$ & 0 & $0,397^{\star *}$ & 0 & $0,295^{* *}$ & 0,001 \\
\hline \multirow[t]{2}{*}{ Complex } & 114 & $0,565^{* *}$ & 0 & 0,252 & 0,055 & $0,432^{* *}$ & 0 \\
\hline & $\begin{array}{l}\text { Simple - Me- } \\
\text { dium }\end{array}$ & p-Value & $\begin{array}{l}\text { Simple - Com- } \\
\text { plex }\end{array}$ & p-Value & $\begin{array}{l}\text { Medium - } \\
\text { Complex }\end{array}$ & p-Value & \\
\hline Q-> D & 0,203 & 0,154 & 0,29 & 0,089 & 0,086 & 0,469 & \\
\hline$D \rightarrow F$ & 0,087 & 0,586 & 0,059 & 0,76 & 0,146 & 0,349 & \\
\hline$F \rightarrow C$ & 0,044 & 0,818 & 0,181 & 0,367 & 0,137 & 0,341 & \\
\hline
\end{tabular}




\section{Type of product development}

\begin{tabular}{|c|c|c|c|c|c|c|c|}
\hline Product development & $\mathrm{N}$ & Q->D & $\mathrm{p}$-Value & $\mathrm{D}->\mathrm{F}$ & p-Value & $\mathrm{F}->\mathrm{C}$ & $\mathrm{p}$-Value \\
\hline $\begin{array}{l}\text { According customer specifi- } \\
\text { cation }\end{array}$ & 242 & $0,502^{* *}$ & 0 & $0,331^{* *}$ & 0 & $0,235^{\star *}$ & 0,001 \\
\hline $\begin{array}{l}\text { As standardized basic pro- } \\
\text { gram incorporating customer } \\
\text { specific option }\end{array}$ & 88 & $0,293^{* *}$ & 0,007 & $0,487 * *$ & 0 & 0,279 & 0,082 \\
\hline \multirow[t]{2}{*}{$\begin{array}{l}\text { For a standard program from } \\
\text { which the customer can } \\
\text { choose }\end{array}$} & 142 & $0,415^{* *}$ & 0 & $0,236^{*}$ & 0,02 & $0,287^{\star *}$ & 0 \\
\hline & $\begin{array}{l}\text { Customer } \\
\text { spec - Basic } \\
\text { program }\end{array}$ & $\mathrm{p}$-Value & $\begin{array}{l}\text { Custom spec } \\
\text { - Standard }\end{array}$ & p-Value & $\begin{array}{l}\text { Basic - } \\
\text { Standard }\end{array}$ & p-Value & \\
\hline Q-> D & 0,209 & 0,088 & 0,087 & 0,379 & 0,122 & 0,341 & \\
\hline $\mathrm{D} \rightarrow \mathrm{F}$ & 0,156 & 0,256 & 0,095 & 0,425 & 0,251 & 0,073 & \\
\hline $\mathrm{F} \rightarrow \mathrm{C}$ & 0,044 & 0,776 & 0,052 & 0,668 & 0,008 & 0,963 & \\
\hline
\end{tabular}

\section{Type of manufacturing process}

\begin{tabular}{|c|c|c|c|c|c|c|c|}
\hline & $\mathrm{N}$ & Q->D & $\mathrm{p}$-Value & $\mathrm{D}->\mathrm{F}$ & p-Value & $\mathrm{F}->\mathrm{C}$ & p-Value \\
\hline Made-to-order & 389 & $0,554^{* *}$ & 0 & $0,379 * *$ & 0 & $0,293^{* *}$ & 0 \\
\hline \multirow[t]{2}{*}{ Made-to stock } & 85 & 0,289 & 0,112 & $0,253^{* *}$ & 0,001 & $0,443^{*}$ & 0,044 \\
\hline & \multicolumn{3}{|c|}{ Make-to order - Make-to-stock } & \multicolumn{4}{|l|}{ p-Value } \\
\hline Q-> D & \multicolumn{3}{|l|}{0,265} & \multicolumn{4}{|l|}{0,052} \\
\hline$D \rightarrow F$ & \multicolumn{3}{|l|}{0,126} & \multicolumn{4}{|l|}{0,439} \\
\hline $\mathrm{F} \rightarrow \mathrm{C}$ & \multicolumn{3}{|l|}{0,15} & \multicolumn{4}{|l|}{0,361} \\
\hline
\end{tabular}

\section{Batch size}

\begin{tabular}{|c|c|c|c|c|c|c|c|}
\hline Batch size & $\mathrm{N}$ & $\mathrm{Q}>\mathrm{D}$ & p-Value & $D->F$ & p-Value & $\mathrm{F}->\mathrm{C}$ & $\mathrm{p}$-Value \\
\hline Single & 119 & $0,514^{\star *}$ & 0 & $0,405^{* *}$ & 0 & $0,422^{* *}$ & 0,001 \\
\hline Small & 289 & $0,478^{* *}$ & 0 & $0,334^{* *}$ & 00 & $0,343^{* *}$ & 0 \\
\hline \multirow[t]{2}{*}{ large } & 76 & $0,492^{* *}$ & 0 & $0,322^{\star *}$ & 0 & $0,217^{* *}$ & 0 \\
\hline & Single - Small & p-Value & Single - Large & p-Value & Small - Large & p-Value & \\
\hline Q-> D & 0,036 & 0,765 & 0,023 & 0,885 & 0,014 & 0,93 & \\
\hline$D \rightarrow F$ & 0,07 & 0,628 & 0,082 & 0,689 & 0,012 & 0,947 & \\
\hline $\mathrm{F} \rightarrow \mathrm{C}$ & 0,079 & 0,563 & 0,205 & 0,342 & 0,126 & 0,521 & \\
\hline
\end{tabular}

\section{Capacity utilization}

\begin{tabular}{|c|c|c|c|c|c|c|c|}
\hline $\begin{array}{l}\text { Capacity } \\
\text { utilization }\end{array}$ & $\mathrm{N}$ & $\mathrm{Q}->\mathrm{D}$ & p-Value & $D->F$ & p-Value & $\mathrm{F}->\mathrm{C}$ & $\mathrm{p}$-Value \\
\hline Less than $90 \%$ & 246 & $0,449 * *$ & 0 & $0,389 * *$ & 0 & $0,284^{* *}$ & 0 \\
\hline More than 90\% & 167 & $0,544^{* *}$ & 0 & $0,346^{* *}$ & 0,001 & $0,336^{*}$ & 0,002 \\
\hline & Low - High & & & $\mathrm{p}$-Value & & & \\
\hline Q-> D & 0,096 & & & 0,398 & & & \\
\hline$D \rightarrow F$ & 0,044 & & & 0,735 & & & \\
\hline $\mathrm{F} \rightarrow \mathrm{C}$ & 0,053 & & & 0,689 & & & \\
\hline
\end{tabular}

